\title{
RESEARCH
}

Open Access

\section{Heat shock preconditioning mesenchymal stem cells attenuate acute lung injury via reducing NLRP3 inflammasome activation in macrophages}

Haijin Lv ${ }^{1,2+}$, Xiaofeng Yuan ${ }^{2,3+}$, Jiebin Zhang ${ }^{2,4+}$, Tongyu Lu ${ }^{2,4+}$, Jia Yao ${ }^{2,4}$, Jun Zheng ${ }^{2,4}$, Jianye Cai ${ }^{2,4}$, Jiaqi Xiao ${ }^{2,4}$, Haitian Chen ${ }^{2,4}$, Shujuan Xie ${ }^{5}$, Ying Ruan ${ }^{6}$, Yuling An ${ }^{1,2^{*}}, \mathrm{Xin}_{\mathrm{Sui}}{ }^{1,2^{*}}$ (D) and Huimin $\mathrm{Yi}^{1,2^{*}}$

\begin{abstract}
Objectives: Acute lung injury (ALI) remains a common cause of morbidity and mortality worldwide, and to date, there is no effective treatment for ALI. Previous studies have revealed that topical administration of mesenchymal stem cells (MSCs) can attenuate the pathological changes in experimental acute lung injury. Heat shock (HS) pretreatment has been identified as a method to enhance the survival and function of cells. The present study aimed to assess whether HS-pretreated MSCs could enhance immunomodulation and recovery from ALI.
\end{abstract}

Materials and methods: $\mathrm{HS}$ pretreatment was performed at $42^{\circ} \mathrm{C}$ for $1 \mathrm{~h}$, and changes in biological characteristics and secretion functions were detected. In an in vivo mouse model of ALI, we intranasally administered pretreated umbilical cord-derived MSCs (UC-MSCS), confirmed their therapeutic effects, and detected the phenotypes of the macrophages in bronchoalveolar lavage fluid (BALF). To elucidate the underlying mechanisms, we cocultured pretreated UC-MSCs with macrophages in vitro, and the expression levels of inflammasome-related proteins in the macrophages were assessed.

Results: The data showed that UC-MSCs did not exhibit significant changes in viability or biological characteristics after HS pretreatment. The administration of HS-pretreated UC-MSCs to the ALI model improved the pathological changes and lung damage-related indexes, reduced the proinflammatory cytokine levels, and modulated the M1/ M2 macrophage balance. Mechanistically, both the in vivo and in vitro studies demonstrated that HS pretreatment enhanced the protein level of HSP70 in UC-MSCS, which negatively modulated NLR family pyrin domain containing 3 (NLRP3) inflammasome activation in alveolar macrophages. These effects were partially reversed by knocking down HSP70 expression.

\footnotetext{
*Correspondence: anyuling929@163.com; drsuixin@126.com;

ylhmin@hotmail.com

${ }^{\dagger}$ Haijin Lv, Xiaofeng Yuan, Jiebin Zhang and Tongyu Lu contributed equally to this work.

'Department of Surgical Intensive Care Unit, the Third Affiliated Hospital of Sun Yat-sen University, Guangzhou 510630, Guangdong Province, China

Full list of author information is available at the end of the article
}

(c) The Author(s). 2021 Open Access This article is licensed under a Creative Commons Attribution 4.0 International License, which permits use, sharing, adaptation, distribution and reproduction in any medium or format, as long as you give appropriate credit to the original author(s) and the source, provide a link to the Creative Commons licence, and indicate if changes were made. The images or other third party material in this article are included in the article's Creative Commons. licence, unless indicated otherwise in a credit line to the material. If material is not included in the article's Creative Commons licence and your intended use is not permitted by statutory regulation or exceeds the permitted use, you will need to obtain permission directly from the copyright holder. To view a copy of this licence, visit http://creativecommons.org/licenses/by/4.0/ The Creative Commons Public Domain Dedication waiver (http://creativecommons.org/publicdomain/zero/1.0/) applies to the data made available in this article, unless otherwise stated in a credit line to the data. 
(Continued from previous page)

Conclusion: HS pretreatment can enhance the beneficial effects of UC-MSCs in inhibiting NLRP3 inflammasome activation in macrophages during ALI. The mechanism may be related to the upregulated expression of HSP70.

Keywords: Heat shock, Umbilical cord-derived mesenchymal stem cells, Acute lung injury, Macrophage, NLRP3 inflammasome

\section{Introduction}

Acute lung injury (ALI) is a common inflammatory disease that is pathologically characterized by diffuse inflammation and subsequently increased vascular permeability in the lung, which lead to reduced alveolar gas exchange and ultimately to the development of acute respiratory distress syndrome (ARDS) [1, 2]. ARDS remains a common and life-threatening lung disease, and the associated mortality rate ranges from 30 to $50 \%[3$, 4]. Although advances in health care, including extracorporeal high-frequency oscillatory ventilation and carbon dioxide removal, have been made, there is still no pharmacological approach that is effective for the treatment of ARDS [5]. Therefore, the exploration of promising therapeutic strategies for targeting these pathophysiological features to alleviate ARDS is urgently needed.

As an imbalance between anti-inflammatory and proinflammatory factors is one of the major characteristics of ARDS, cytokine modulation may become a potential treatment approach [6]. Alveolar macrophages, which are the main components of the lung immune system and are located at the air-tissue interface, play heterogeneous roles in lung injury, as their various functions depend on their phenotypes and the cytokines they secrete $[7,8]$. In a murine model of ALI, proinflammatory macrophages (M1-polarized) predominately reside in the lung and induce pulmonary injury; however, these cells are repolarized and express surface markers associated with a reparative phenotype (M2-polarized) during the resolution of ALI [9]. Treatment with mesenchymal stem cells (MSCs) might be an ideal therapeutic approach because of their potential to contribute to immunoregulation and tissue repair. Our previous studies yielded reliable results on the beneficial effects of MSCs on ameliorating liver ischemia/reperfusion injury (IRI) in vivo and in vitro $[10,11]$. In addition, we and others have also shown that MSCs can alleviate lipopolysaccharide (LPS)-induced ALI via their well-defined role in immunomodulation and their ability to differentiate into multiple different cell types, including adipocytes, osteoblasts and lung-related cell types [12-17].

Indeed, recent studies have focused on how to enhance the therapeutic effects of MSCs in various diseases. In a previous study, we demonstrated that preconditioning MSCs with rapamycin could increase their hepatoprotective effects against liver IRI by enhancing their immunosuppressive function and strengthening their migratory capacity [18]. Heat shock (HS) has also been identified as an effective method by which to increase cell survival and enhance cell function in vitro in various culture environments [19,20]. Several studies reported that HS pretreatment of transfused MSCs enhanced their survival following administration to liver IRI and chemotherapy-induced granulosa cell apoptosis models [21, 22]. Other findings have revealed that HS pretreatment of transplanted cells could strengthen their therapeutic effects [23]. However, whether HS pretreatment enhances the ability of MSCs to protect against ALI is still unknown.

The aim of this study was to investigate the protective effects of HS-pretreated umbilical cord-derived MSCs (UC-MSCs) in alleviating ALI and the potential underlying mechanisms. We hypothesized that HS not only maintains the viability of MSCs but also enhances the pulmonary protective effects of MSCs during ALI by modulating the NLRP3 inflammasome in macrophages.

\section{Methods and materials \\ Isolation and culture of UC-MSCs}

The UC-MSC isolation procedures were conducted according to the Declaration of Helsinki and were approved by the Research Ethics Committee of the Third Affiliated Hospital of Sun Yat-sen University (Guangzhou, China). All these procedures were performed under aseptic conditions according to previously described methods [24]. After obtaining informed consent from the patients, fresh umbilical cords (UCs) were obtained and immersed in phosphate-buffered saline (PBS) at $4{ }^{\circ} \mathrm{C}$. After removing the remnant blood by washing with PBS, the UCs were cut into $10-\mathrm{mm}^{3}$ pieces and placed in type I collagenase (Sigma, USA) with $0.1 \%$ hyaluronidase and $3 \mathrm{mM} \mathrm{CaCl}$ and digested at $37^{\circ} \mathrm{C}$ for $4 \mathrm{~h}$. The samples were incubated in low-glucose Dulbecco's modified Eagle's medium (DMEM, $1 \mathrm{~g} / \mathrm{L}$, Gibco, Life, Australia) with $10 \%$ fetal bovine serum (FBS, PANBiotech, Germany) at $37^{\circ} \mathrm{C}$ in $5 \% \mathrm{CO}_{2}$ in a humidified atmosphere. The medium was replaced every 3 days to remove the nonadherent cells, while the remaining adherent cells were cultured and passaged. 


\section{Preparation of HS-pretreated UC-MSCs}

The procedure for preparing HS-pretreated UC-MSCs was performed as previously described [25]. In brief, UC-MSCs in the 3rd passage were collected, and the culture medium was replaced to remove the nonadherent cells. Then, the cells were exposed to HS conditions for $1 \mathrm{~h}$ in a $42^{\circ} \mathrm{C}$ water bath and subsequently cultured at $37^{\circ} \mathrm{C}$ in $5 \% \mathrm{CO}_{2}$ in a humidified atmosphere for $48 \mathrm{~h}$. The control group included UC-MSCs incubated under typical conditions without HS pretreatment (Fig. 2a).

\section{Cytotoxicity assay}

CCK-8 assay: UC-MSCs were plated in 96-well plates at a density of 2000 cells/well. A Cell Counting Kit-8 (CCK-8, Kaiji Bio-Technology Co. Ltd., Jiangsu, China) was conducted after 12, 24, and $48 \mathrm{~h}$ of treatment according to the manufacturer's protocol. The optical density (OD) was measured at $450 \mathrm{~nm}$ using an automatic microplate reader (Biotek Vermont, USA). PI/ Annexin V: UC-MSCs were stained with Annexin V/ propidium iodide to quantify cell apoptosis in each group following the manufacturer's instructions. In brief, UC-MSCs were cultured in 6-well plates, treated according to the experimental design for each group for $48 \mathrm{~h}$, harvested, and stained with Annexin V/PI (Kaiji BioTechnology) for $15 \mathrm{~min}$. The apoptosis rate was detected by flow cytometry.

\section{Multipotential differentiation of UC-MSCs}

To detect the adipogenic and osteogenic differentiation potential of the cells, UC-MSCs were incubated with media that specifically induced adipogenesis and osteogenesis (Gibco, Life Technologies, NY, USA), respectively. The medium of each specimen was replaced every 3 days. The ability of the UC-MSCs to differentiate into adipocytes and osteocytes was evaluated by Oil Red $\mathrm{O}$ and Alizarin Red S, respectively, after 14 or 21 days of incubation. For chondrogenic differentiation, 500,000 cells were pelleted in $15 \mathrm{~mL}$ conical tubes via centrifugation at $400 \mathrm{~g}$ for $10 \mathrm{~min}$. After $48 \mathrm{~h}$ in the appropriate basal medium for the cell type, chondrogenesis was induced with chondrogenic media containing of DMEM, as described previously. Pellets were maintained in culture for 28 days, and fixed in a $10 \%$ formalin solution prior to paraffin embedding and sectioning. Pellets were then stained with toluidine blue.

\section{Flow cytometry analysis}

The cell surface antigens of the UC-MSCs were detected using flow cytometry analysis. After reaching $70-80 \%$ confluence, the cultured cells were trypsinized and incubated with monoclonal antibodies, including PE-Cy7CD34, PE-CD29, PE-Cy7-CD45, APC-CD44, APCCD90, FITC-CD105, and FITC-CD73, for $30 \mathrm{~min}$ at $4{ }^{\circ} \mathrm{C}$ in the dark. Flow cytometry analysis was performed using an eight-color FACSCalibur ${ }^{\text {rm }}$ flow cytometer (BD Biosciences, NJ, USA).

We also used flow cytometry analysis to detect changes in macrophage polarization in vivo and in vitro. For surface marker staining, cells were harvested from both bronchoalveolar lavage fluid (BALF) and in vitro experiments and were incubated with primary APCCD206 and PE-CD11b antibodies at $4{ }^{\circ} \mathrm{C}$ for $30 \mathrm{~min}$ in the dark. The fluorescence of the cells was evaluated using an eight-color FACSCalibur ${ }^{\mathrm{Tn}}$ flow cytometer.

All the data were analyzed using FlowJo 7.6 software (Becton Dickinson, USA).

\section{Quantitative real-time reverse transcriptase-polymerase chain reaction}

Total RNA extraction and quantitative real-time reverse transcriptase-polymerase chain reaction (qRT-PCR) were conducted following a previous report [18]. Total RNA was extracted from UC-MSCs and macrophages using TRIzol (Invitrogen) according to the manufacturer's protocol. A Biophotometer Plus (Eppendorf, Germany) was used to detect the amount and purity of the total RNA at absorbance wavelengths of $260 \mathrm{~nm}$ and $280 \mathrm{~nm}$. Then, the RNA was reverse transcribed into cDNA by a Transcriptor First-Strand cDNA Synthesis Kit (Roche, Applied Science, USA), and the cDNA was amplified for $10 \mathrm{~min}$ at $65^{\circ} \mathrm{C}$, incubated at $55^{\circ} \mathrm{C}$ for $30 \mathrm{~min}$, deactivated at $85^{\circ} \mathrm{C}$ for $5 \mathrm{~min}$, and finally stored at $4{ }^{\circ} \mathrm{C}$ for 5 min in a PCR thermal cycler (Bio-Rad, USA). RT-qPCR was conducted with SYBR Master Mix (Roche Applied Science) using a reverse transcription system (LC-480, Roche, USA). $\beta$-actin was used as the housekeeping gene. The sequences of the target gene-specific primers used in this study are shown in Supplementary Table 1.

\section{Enzyme-linked immunosorbent assay}

Enzyme-linked immunosorbent assay (ELISA) was performed as previous published criteria [26]. The levels of IL-10, PEG2, and TGF- $\beta$ in the MSC-conditioned medium (MSC-CM) and the concentrations of TNF- $\alpha$, IL- $1 \beta$, and IL- 6 in the supernatants and BALF were measured using ELISA kits following the manufacturer's instructions (EIAAB Science Company, Wuhan, China). An automatic microplate reader (Biotek, Vermont, USA) was used to detect the optical density (OD) at $450 \mathrm{~nm}$.

\section{Immunoblotting}

Lung tissues and macrophages were lysed with cold radioimmunoprecipitation assay (RIPA) buffer containing $50 \mathrm{mM}$ Tris- $\mathrm{HCl}$ (pH 7.4), $150 \mathrm{mM} \mathrm{NaCl}, 0.1 \%$ Triton $\mathrm{X}-100,10 \%$ SDS, $10 \%$ sodium deoxycholate, $2 \mathrm{mM}$ EDTA, and a protease inhibitor cocktail (Roche, Basel, Switzerland). Equal amounts of proteins were subjected 
to $12 \%$ SDS polyacrylamide gel electrophoresis (PAGE) and subsequently transferred onto polyvinylidene difluoride (PVDF) membranes (Millipore, Billerica, MA, USA). After incubation in $5 \%$ nonfat milk for $1 \mathrm{~h}$ to block nonspecific antigens, the membranes were incubated with primary antibodies, including antibodies against NLRP3, ACS, pro-Caspase 1, cleaved Caspase 1, and IL- $1 \beta$, at $4{ }^{\circ} \mathrm{C}$ overnight. After washing three times with tris-buffered saline with tween (TBST), the membranes were incubated with the secondary antibodies (1: 5000, Sigma-Aldrich) for $1 \mathrm{~h}$ at room temperature. Then, the membranes were incubated with an enhanced chemiluminescence (ECL) substrate, and the blots were visualized using a FluorChem System imager (ProteinSimple, CA, USA). ImageJ software (USA) was used to analyze the intensities of the bands.

\section{Animals}

C57BL/6 mice (B6 mice, male, 8-10 weeks, 22-25 g) were purchased from Biomedical Research Institute of Nanjing University (Jiangsu, China). All the mice were housed in the Laboratory Animal Center of South China Agricultural University under specific pathogen-free (SPF) conditions and were cared for according to the Guideline of South China Agricultural University for Animal Experimentation. The animals were maintained in an environment with a constant temperature $\left(20^{\circ} \mathrm{C}\right)$, humidity $(50 \%)$, and dark and light cycle $(12 \mathrm{~h})$ and received free access to a standard laboratory diet and water.

\section{LPS-induced ALI model and BALF collection}

All the animal experiments were conducted according to the guidelines of the Ethics Committee on Animal Welfare, South China Agricultural University. The standard procedures for establishing a mouse model of LPSinduced ALI were performed as previously described [27]. In brief, the mice were anesthetized by intraperitoneal injection of pentobarbital sodium $(0.1 \%, 100 \mu \mathrm{l} / 10$ g) and then divided into four groups: $\mathrm{PBS}+\mathrm{PBS}$, lipopolysaccharide (LPS) + PBS, LPS + UC-MSCs, and LPS + HS-UC-MSCs. The mouse model of ALI was established by intranasally dripping LPS ( $5 \mathrm{mg} / \mathrm{kg}$, Sigma, USA). The sham group was treated with the same volume of PBS. After $4 \mathrm{~h}$ of treatment, the mice were intranasally administered UC-MSCs $\left(1 \times 10^{4} / 30 \mu \mathrm{l}\right)$, PBS $(30 \mu \mathrm{l})$ or HSUC-MSCs $\left(1 \times 10^{4} / 30 \mu \mathrm{l}\right)$ according to the experimental design of each group mentioned above. The mice in the four groups were euthanized $24 \mathrm{~h}$ after model establishment.

To collect the BALF, an intravenous infusion needle (BD, USA) was used to flush the lung 3 times with 0.5 $\mathrm{ml}$ of PBS prechilled at $4{ }^{\circ} \mathrm{C}$ through the trachea. After centrifugation at $500 \mathrm{~g}$ for $10 \mathrm{~min}$ at $4{ }^{\circ} \mathrm{C}$, the supernatant of the BALF was removed, and the cells were resuspended in ice-cold PBS. The total number of cells was counted using a hemocytometer, and the number of neutrophils was counted after Wright-Giemsa staining.

\section{Lung wet/dry weight ratio evaluation}

The lung wet/dry weight ratio was calculated to evaluate the severity of lung edema. In brief, lung tissues were obtained immediately after the mice were sacrificed, and the wet weight value was recorded. Then, the samples were placed in a $65^{\circ} \mathrm{C}$ incubator for $72 \mathrm{~h}$, and the dry weight value was recorded.

\section{Lung histopathology and injury scoring}

Four-micrometer-thick paraffin-embedded lung tissue sections were prepared and stained with hematoxylin and eosin (H\&E). The histological scores, which indicated the severity of lung injury, were determined according to a previous study; this score was calculated after assessing hyaline membrane formation, alveolar and interstitial inflammation and hemorrhage, necrosis, atelectasis, and edema [28]. The slides were evaluated under a light microscope by an observer who did not know the experimental design of the groups. Five fields were selected from each section to calculate the injury score. Lung injury scores were quantified by an investigator blinded to the treatment groups using published criteria, which gives an overall score of between 0 and 1 [29].

\section{Fluorescent TUNEL staining}

To investigate cell apoptosis in the lung, we performed a fluorescent TUNEL (terminal deoxynucleotidyl transferase-mediated dUTP nick end labeling) assay using a commercial in situ apoptosis detection kit (Roche Diagnostics, Indianapolis, IN, USA) on 16- $\mu$ mthick cryosections. Briefly, after washing with equilibration buffer, the cryosections were incubated with the TUNEL reaction mixture, including the enzyme and label solution, for $60 \mathrm{~min}$ in the dark at $37^{\circ} \mathrm{C}$. Then, the sections were treated with DAPI for $2 \mathrm{~min}$ in the dark and mounted using Prolong Diamond Antifade Mounting Agent. The slides were investigated under a fluorescent inverted microscope (Leica, Germany).

\section{Cell coculture experiments}

UC-MSCs or HS-pretreated UC-MSCs were seeded on a Transwell insert $\left(0.4 \mu \mathrm{m}\right.$, Corning) at a density of $4 \times 10^{5}$ cells/ml. Human THP-1 monocytic cells (ATCC, Manassas, VA, USA) were cultured in T-75 flasks in RPMI 1640 (Sigma-Aldrich, St. Louis, MO, USA) containing $10 \%$ FBS, $1 \%$ penicillin/streptomycin, and $50 \mu \mathrm{M} \beta$ mercaptoethanol (Sigma-Aldrich, St. Louis, MO, USA) incubating at $37^{\circ} \mathrm{C}$ in a $95 \%$ humidified atmosphere and 
5\% $\mathrm{CO}_{2}$. Cells were subcultured when they reached a concentration of $8 \times 10^{5}$ cells $/ \mathrm{ml}$. In addition, the THP- 1 macrophage cell line was plated in the lower chamber of a 6-well plate at a concentration of $5 \times 10^{5}$ cells $/ \mathrm{ml}$ and stimulated with PMA $(50 \mathrm{ng} / \mathrm{ml})$ for $24 \mathrm{~h}$. Then, the upper chamber containing cultured UC-MSCs and HSUC-MSCs was placed in the 6-well plate, cocultured with the THP-1 cells, and treated with LPS $(1 \mu \mathrm{g} / \mathrm{ml})$ and IFN- $\gamma(50 \mathrm{ng} / \mathrm{ml})$ for $24 \mathrm{~h}$ [30]. Finally, the THP-1 cells were harvested using EDTA $(0.5 \mathrm{mM})$.

\section{Statistical analysis}

The data are presented as the mean \pm standard error of the mean (SEM) or as direct values. As appropriate, differences between groups were compared using unpaired two-tailed Student's $t$ test or one-way analysis of variance (ANOVA). A probability value ( $p$ value) $<0.05$ was considered statistically significant. The statistical analyses were conducted using GraphPad Prism 7 software (GraphPad Software, San Diego, CA).

\section{Results}

\section{Culture and identification of UC-MSCs}

As shown in Fig. 1a, the UC-MSCs were identified as a population of fibroblast-like cells. After incubation for 14 days, 21 days, or 28 days in specific media, the cells differentiated into adipocytes, osteocytes, or chondrocytes, as shown by staining with Oil red O, Alizarin Red solution, and toluidine blue, respectively. Examination of their cell surfaces showed positive expression of CD73, CD90, CD29, CD105, and CD44 and negative expression of CD34, CD45, and HLA-DR (Fig. 1b).

\section{The biological features and viability of HS-pretreated UC- MSCs}

As shown in Fig. 1c, pretreatment with HS for $1 \mathrm{~h}$ and subsequent culture under typical conditions for $48 \mathrm{~h}$ did not affect the morphology, the multi-differentiation potential (Fig. 1d), or surface characteristics of the UCMSCs (Fig. 1e). The CCK-8 assay showed that there was no significant difference in the cell proliferation rate between the UC-MSCs cultured under typical conditions and the HS-pretreated UC-MSCs (Fig. 1f). The flow cytometry results revealed that the apoptotic rate of the HS-pretreated UC-MSCs was not significantly different from that of the control cells (Fig. 1g).

\section{Administration of HS-pretreated UC-MSCs attenuates LPS- induced ALI}

We assessed the severity of lung injury in each group to determine whether HS-pretreated UC-MSCs can improve pulmonary function after LPS administration. A mouse model of ALI was established by the intratracheal injection of LPS. After $24 \mathrm{~h}$, lung injury was pathologically confirmed and was characterized by lung edema, widespread septal thickening, and neutrophil/mononuclear infiltration into alveolar spaces; however, these changes were significantly improved after the administration of UC-MSCs, and treatment with HS-pretreated UC-MSCs led to the enhanced recovery of these histopathological changes (Fig. 2a). The lung injury score, which was evaluated based on H\&E staining of lung sections, showed consistent results (Fig. 2b). Moreover, the results showed that LPS induced an increase in the lung wet/dry weight ratio in the mice, while UC-MSCs significantly ameliorated pulmonary edema (Fig. 2c). Interestingly, a better therapeutic effect was observed in the HS-pretreated UC-MSC group than in the UC-MSC group (Fig. 2c). Exchange in BALF is an important indicator for assessing lung function. The results from cell smears showed that HS pretreatment could further enhance the UC-MSC-induced decrease in the BALF inflammatory cell count (Fig. 2d). In addition, a TUNEL assay was performed to evaluate endothelial apoptosis in each group. As shown in Fig. 2e, the apoptotic index of the lung endothelium obviously increased after exposure to LPS, whereas the increased index was markedly decreased after treatment with UCMSCs. Moreover, in mice administered HS-pretreated UC-MSCs, the apoptotic index of the lung endothelium was significantly lower than that in the mice administered UC-MSCs. These results demonstrated that HS pretreatment plays a critical role in enhancing the lung-protective effects of UC-MSCs.

\section{HS-pretreated UC-MSCs modulate the functions of alveolar macrophages in vivo and in vitro}

Increasing evidence has demonstrated that the polarization of alveolar macrophages is a critical factor that affects the pathological process of ALI [31]. Thus, we next collected BALF and detected changes in the alveolar macrophage phenotypes in each group. The flow cytometry results showed that UC-MSCs promoted the expression of the anti-inflammatory marker CD206 (Fig. 3a) and decreased the LPS-induced increased expression of the proinflammatory marker TNF- $\alpha$ in alveolar macrophages (F4/80+) (Fig. 3b). Compared with UCMSCs cultured under typical conditions, UC-MSCs pretreated with HS exhibited an enhanced immunoregulatory effect in inducing M2 macrophage polarization (Fig. 3a, b). Furthermore, we detected the concentrations of several cytokines to indirectly evaluate the secretion function of alveolar macrophages. As shown in Fig. 3c, LPS promoted the secretion of various cytokines, including TNF- $\alpha$, IL- $1 \beta$, and IL- 6 , from macrophages, and UCMSCs reversed these changes in macrophage secretion. As expected, HS pretreatment further enhanced these 

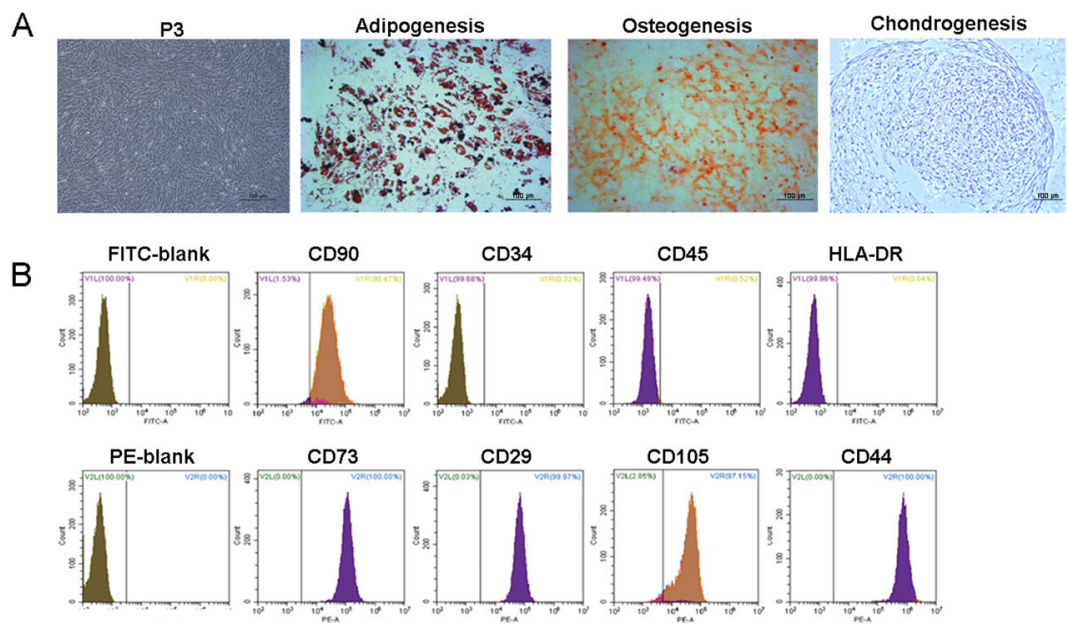

C
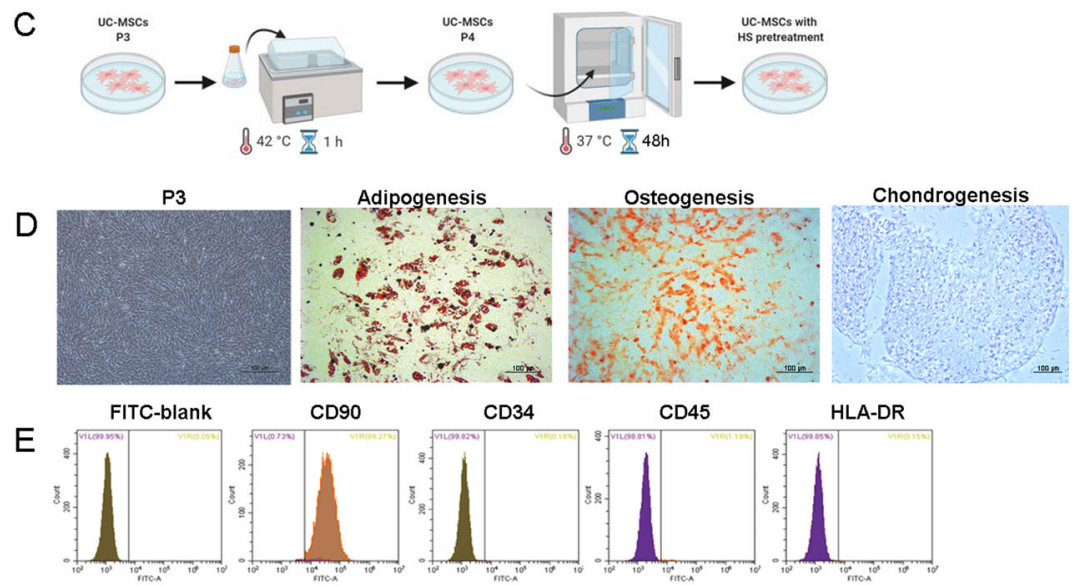

CD90

CD34

CD45

HLA-DR
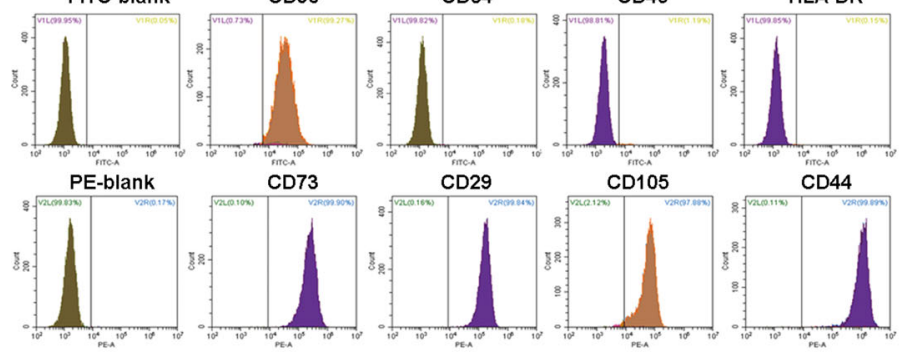

$\mathrm{F}$
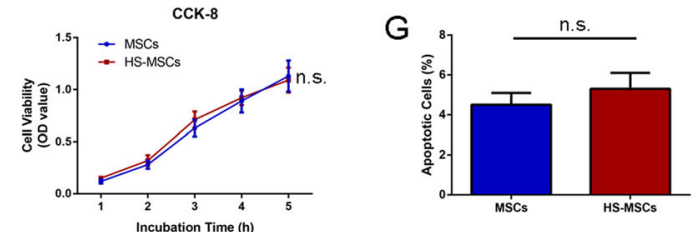

Fig. 1 The optimal condition of HS pretreatment did not affect the viability and biological characteristics of UC-MSCs. a The fibroblast-like morphology and multi-differentiation potential of cultured UC-MSCs. Oil red O staining of UC-MSCs cultured in medium that specifically induced adipogenesis 14 days. Alizarin Red solution staining of UC-MSCs cultured in medium that specifically induced osteogenesis for 21 days. UC-MSC pellets induced chondrogenesis 28 days stained with toluidine blue (scale bar $=100 \mu \mathrm{m})$. b Flow cytometry analysis of the surface markers of UC-MSCs. c The procedure for obtaining HSpretreated UC-MSCs. d Representative images of HS-pretreated UC-MSCs, which differentiated via adipogenesis, osteogenesis, and chondrogenesis (scale bar $=100 \mu \mathrm{m})$. e Flow cytometry analysis of the surface markers of HS-pretreated UC-MSCs. $\mathbf{f}$ UC-MSCs and HS-pretreated UC-MSCs were subjected to a CCK-8 assay after 0,1 , and 2 days of culture to assess cellular viability. $\mathbf{g}$ The apoptosis rate of each group was detected using Annexin V/propidium iodide staining. The data are presented as the mean \pm SEM. ns, not significant (all $p$ values were obtained by unpaired two-tailed Student's $t$ test)

immunoregulatory effects of UC-MSCs. We further used LPS-stimulated THP-1 cells (macrophage cell line) as an in vitro model and also detected the levels of M2 markers in each group. After stimulation, the expression of CD206 was significantly increased in macrophages cocultured with non-pretreated UC-MSCs compared to control macrophages, and this effect was further enhanced in macrophages after coculture with HS- 

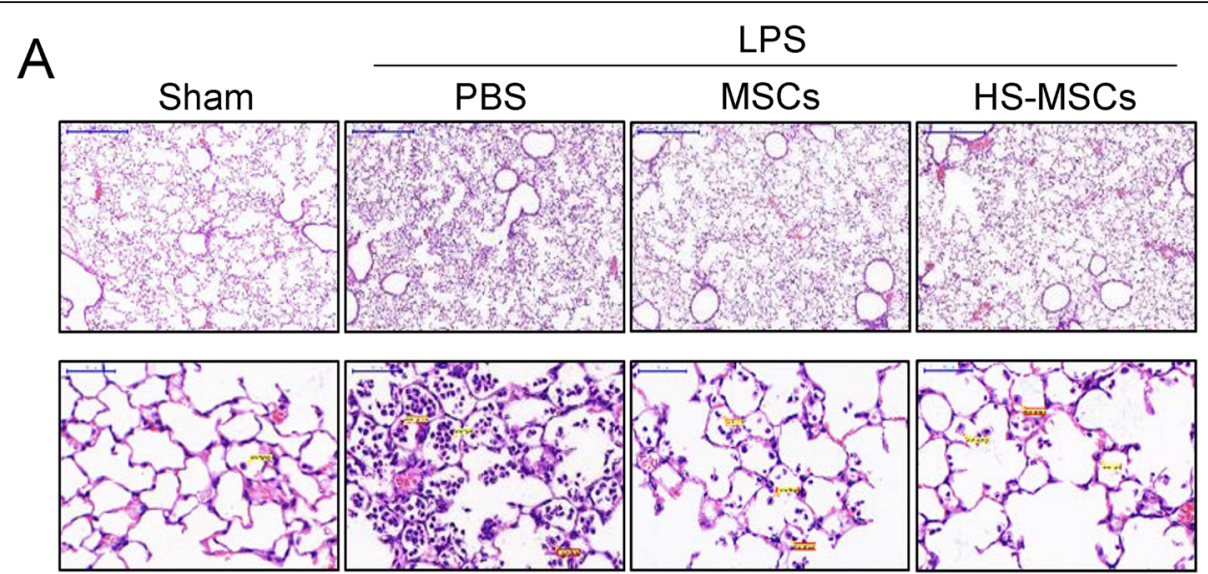

B
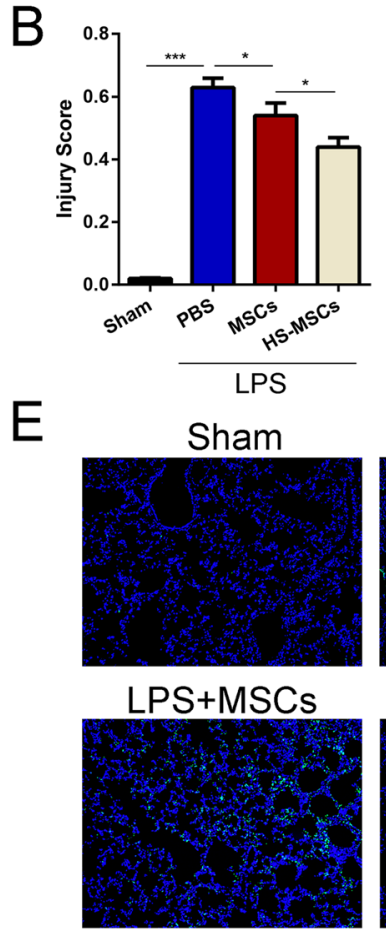
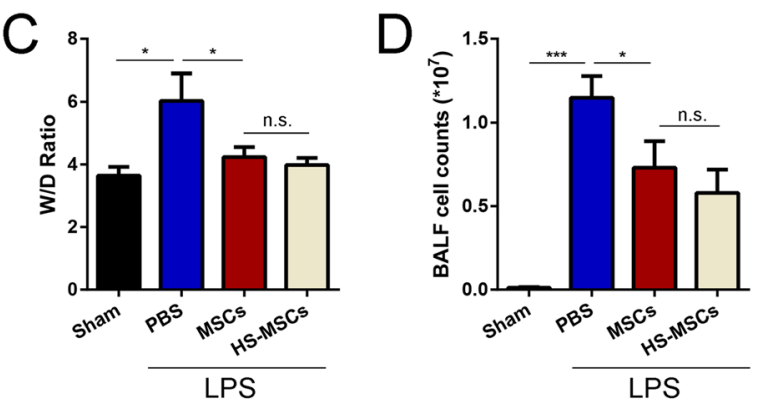

\section{LPS+PBS}
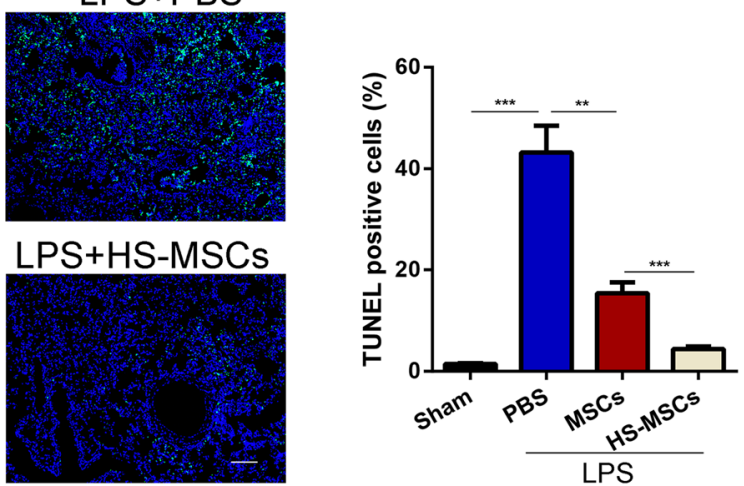

Fig. 2 HS-pretreated UC-MSCS attenuate LPS-induced ALI. a Hematoxylin and eosin staining of lung tissues in each group to assess the amount of lung damage after ALI. Scale bar $200 \mu \mathrm{m}$. b The lung injury score of each group was calculated by selecting five fields in each section. The results are presented as the mean \pm SEM ( $n=5$ mice/group). $\mathbf{c}$ The wet/dry ratio of lung tissue of each group was obtained to evaluate lung edema. The results are presented as the mean \pm SEM ( $n=5$ mice/group). $\mathbf{d}$ The total cell count and neutrophil count in the BALF from each group were examined at $24 \mathrm{~h}$ after LPS treatment to assess the inflammatory response. The results are presented as the mean \pm SEM ( $n=5$ mice/ group). e Representative images of TUNEL staining of lung sections from each group were collected. Scale bar $200 \mu \mathrm{m}$. The data are presented as the mean \pm SEM ( $n=5$ mice/group). ${ }^{*} p<0.05,{ }^{* *} p<0.01,{ }^{* * *} p<0.001$ (all $p$ values were obtained by one-way ANOVA)

pretreated UC-MSCs (Fig. 3d). The levels of M1 markers were significantly increased after treatment with LPS compared with the control, while coculture with nonpretreated or HS-pretreated UC-MSCs significantly reversed this effect (Fig. 3e). In model of co-cultured with MSCs, we detected the mRNA level of inflammatory cytokines mRNA expression in THP-1. The results showed that the HS-MSC could further decrease the mRNA level of TNF- $\alpha$, IL-1 $\beta$, and IL-6 in THP-1 cells (Fig. 3f).
Meanwhile, to detect whether LPS-preconditioned MSCs also have some cytoprotective effects, we collected the conditioned medium (CM) from HS-MSCs to treat THP-1 and analyze the inflammatory cytokines mRNA expression by RT-qPCR. The results showed similar with co-cultured experiments (Fig. 3g). These results suggested that HS pretreatment enhances the effects of UCMSCs in modulating the polarization and secretion functions of alveolar macrophages. 


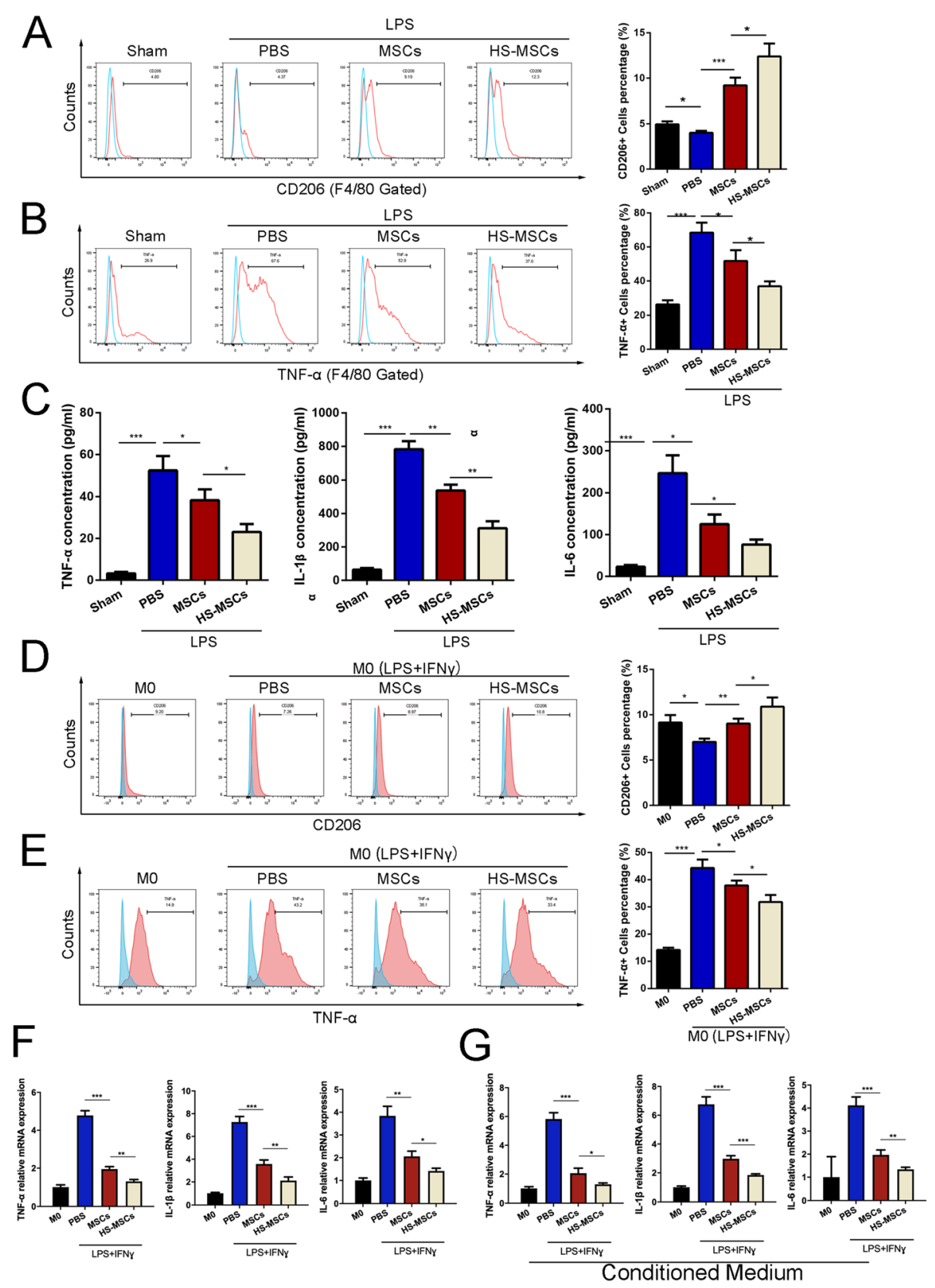

Fig. 3 HS-pretreated UC-MSCs modulate the phenotypic polarization and secretion function of alveolar macrophages. The surface markers CD206 (a) and TNF-a (b) of alveolar macrophages from BALF were detected by flow cytometry analysis. The data are presented as the mean \pm SEM $(n=$ 5 mice/group). c The levels of TNF-a, IL-1 $\beta$, and IL- 6 in BALF from each group were measured by ELISA. The data are presented as the mean \pm SEM ( $n=5$ mice/group). Flow cytometry analyses of CD206 (d) and TNF-a (e) expression in macrophages in each group. $\mathbf{f}$ The mRNA expression of TNF- $\alpha$, IL-1 $\beta$, and IL-6 in THP-1 cells co-cultured with each group of MSCs. $\mathbf{g}$ The mRNA expression of TNF-a, IL-1 $\beta$, and IL-6 in THP-1 cells treated with conditioned medium from each group of MSCs. The data are presented as the mean \pm SEM $\left(n=3 /\right.$ group). ${ }^{*} p<0.05,{ }^{* *} p<0.01$, ${ }^{* * *} p<0.001$ (all $p$ values were obtained by one-way ANOVA)

\section{HS-pretreated UC-MSCs reduce the activation of the NLRP3 inflammasome in macrophages}

It is known that the expression of the components of the NLRP3 inflammasome is positively associated with the severity of ALI [32], and MSCs can significantly reduce NLRP3 inflammasome component expression. Therefore, we further investigated whether HS pretreatment enhanced the therapeutic effect of UC-MSCs on NLRP3 inflammasome activation. As shown in Fig. 4a, b, the increase in the protein expression of NLRP3, ASC, 
pro-Caspase 1, and cleaved-Caspase 1 in the lung tissues lysis solution after LPS exposure was markedly decreased after treatment with UC-MSCs, whereas the expression of these proteins in the HS-pretreated UC-MSC group was significantly lower than that in the UC-MSC group.

In previous studies, NLRP3 inflammasome components were demonstrated to be mainly expressed in activated macrophages. Thus, we also detected the effects of HS-pretreated UC-MSCs on NLRP3 inflammasome activation in a macrophage cell line (THP-1 cells) in vitro (Fig. $4 \mathrm{c}$ and d). The immunoblotting results showed that the increased NLRP3 activation in macrophages, as evidenced by the increased expression of NLRP3, ASC, pro-Caspase 1 , cleaved-Caspase 1 , and IL-1 $\beta$, was obviously suppressed by UC-MSC treatment. Pretreatment with HS enhanced the effects of UC-MSCs in reducing
NLRP3 inflammasome activation in macrophages. Together, these results indicate that HS pretreatment enhances the lung protective capacity of UC-MSCs in the ALI model by inhibiting the activation of the NLRP3 inflammasome in macrophages.

HS pretreatment enhances the secretion abilities of UCMSCs by increasing HSP70 expression

We further explored the potential mechanism by which HS-pretreated UC-MSCs ameliorate ALI and reduce NLRP3 inflammasome activation in macrophages. In previous studies, both IL-10 and PGE2 were shown to negatively regulate inflammasome activation $[33,34]$. Therefore, in this study, we detected the levels of IL-10, TGF- $\beta$, and PGE2 in culture supernatants to evaluate the secretion abilities of UC-MSCs in the presence or absence of HS. The ELISA results showed that

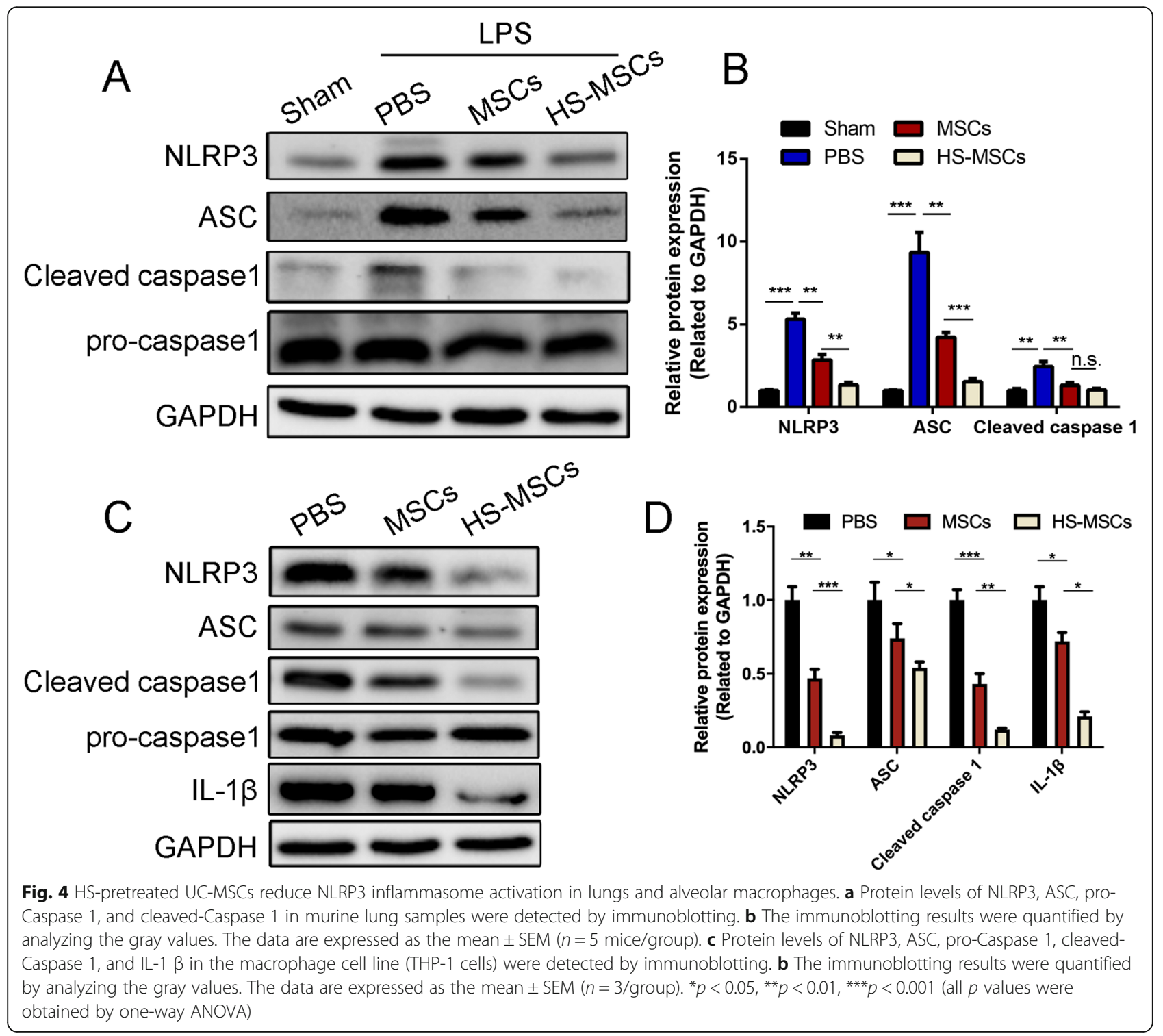


compared with the control group, HS pretreatment caused UC-MSCs to synthesize and secrete notable levels of IL-10 and PGE2 but not TGF- $\beta$ (Fig. 5a). In addition, as Fan et al. demonstrated that HSP70 promoted PGE2 production by regulating COX-2 [35, 36], we targeted the expression of HSP70 in the UC-MSCs in each group. To test the function of HSP70 in HSpretreated UC-MSCs, HSP70 expression was reduced in MSCs using a lentivirus carrying a short hairpin RNA against HSP70 (shHSP70). The efficiency of HSP70 knockdown was confirmed by immunoblotting and RTqPCR (Fig. 5b).
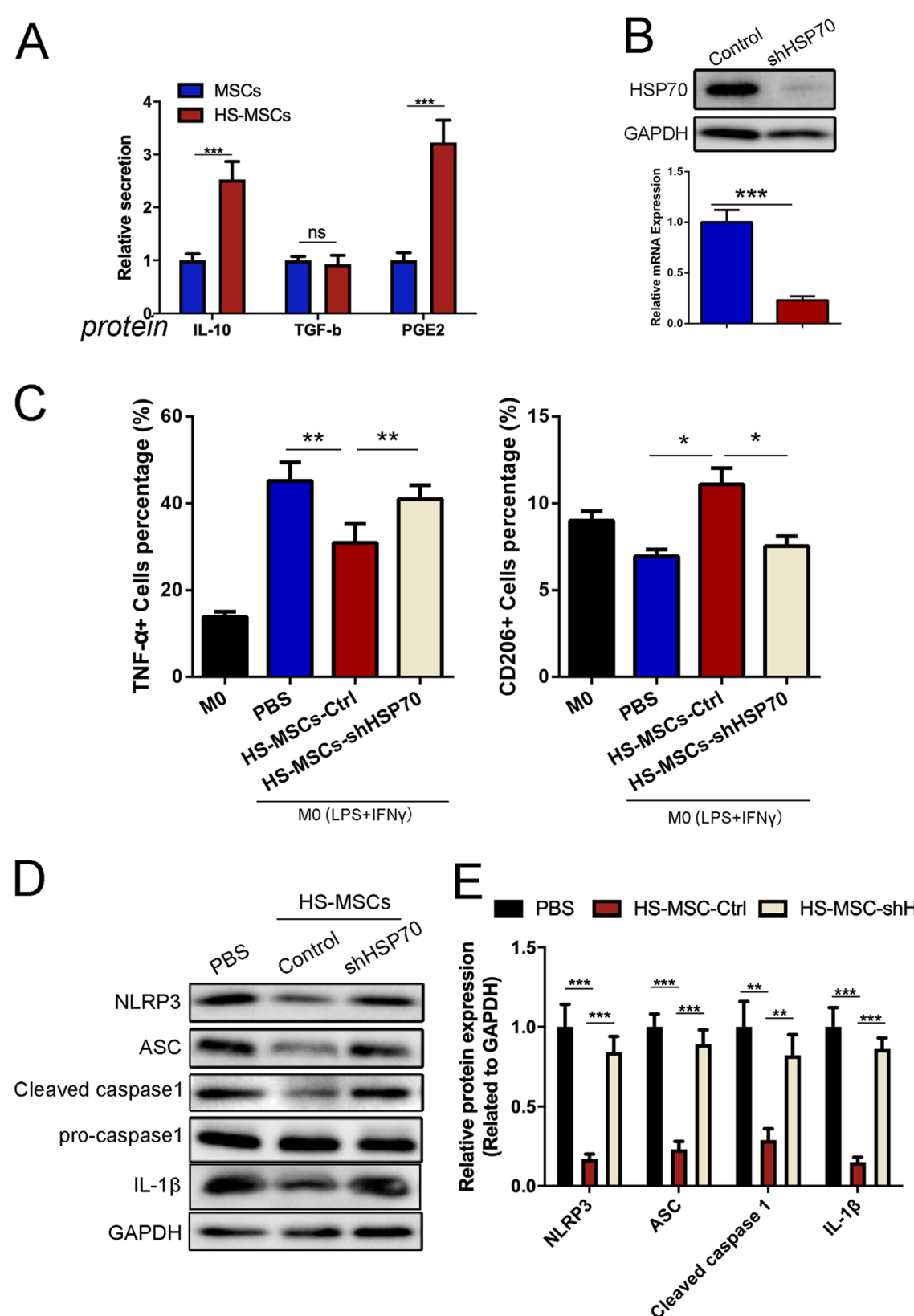

Fig. 5 HS pretreatment enhanced the secretion abilities of UC-MSCs by increasing HSP70 expression. a The levels of IL-10, TGF- $\beta$, and PGE2 in UC-MSC culture supernatants from each group were measured by ELISA. The data are presented as the mean \pm SEM $(n=3 /$ group). $\mathbf{b}$ Protein levels of HSP70 in UC-MSCs after knockdown of HSP70 were detected by immunoblotting. The immunoblotting results were quantified by analyzing the gray values. The data are expressed as the mean \pm SEM ( $n=3 /$ group). c Flow cytometry analyses of TNF-a and CD206 expression in macrophages of each group. The data are presented as the mean \pm SEM ( $n=3 /$ group). d Protein levels of NLRP3, ASC, pro-Caspase 1, cleavedCaspase 1 , and IL-1 $\beta$ in macrophages were detected by immunoblotting. The immunoblotting results were quantified by analyzing the gray values. The data are expressed as the mean \pm SEM ( $n=3 /$ group). ${ }^{*} p<0.05$, ${ }^{* *} p<0.01$, ${ }^{* *} p<0.001$ (all $p$ values were obtained by one-way ANOVA) 
Compared to the HS-pretreated UC-MSCs, the shHSP70-expressing MSCs significantly rescued the decreased TNF- $\alpha$ secretion in the THP-1 macrophages. The expression of CD206 was significantly increased in the macrophages cocultured with HS-pretreated UCMSCs compared to the control macrophages, and this change was reversed in macrophages cocultured with HS-pretreated shHSP70 MSCs (Fig. 5c). We also performed an immunoblotting assay to detect the inflammasome activation of the macrophages in each group. The results indicated that shHSP70 might reverse the effect of HS-pretreated UC-MSCs in reducing NLRP3 inflammasome activation in macrophages (Fig. 5d, e).

\section{Inhibition of HSP70 weakens the protective effect of HS- pretreated UC-MSCs in attenuating LPS-induced ALI}

Furthermore, we also evaluated the degree of lung injury in each group to explore whether HS pretreatment of UC-MSCs attenuates LPS-induced ALI by regulating HSP70. The results showed that HSP70 knockdown abolished the protective effect of HS-pretreated UCMSCs, compared with NTC UC-MSC, as evidenced by the exacerbated pathological changes in the lung architecture (H\&E staining and injury score) and the increased lung wet/dry weight ratio (Fig. 6a-c). In addition, HSP70 knockdown reversed the HS-pretreated UC-MSC-mediated reduction in BALF inflammatory cell counts (Fig. 6d). The results of investigating TUNELpositive cells indicated that the role of HS-pretreated UC-MSCs in protecting alveolar epithelial cells was weakened by knocking down HSP70 (Fig. 6e). In addition, we also performed ELISAs to evaluate the inflammatory response, and the results showed that the significant decreases in proinflammatory cytokines, including TNF- $\alpha$, IL-1 $\beta$, and IL- 6 , induced by HSpretreated UC-MSCs in this ALI model were markedly reversed after HSP70 knockdown (Fig. 6f).

\section{Discussion}

To date, ALI remains one of the most serious respiratory inflammatory syndromes and is known to be a major factor affecting mortality. The current medical therapeutic approaches are not able to halt the progression of ALI [5]. Therefore, exploring optimal therapeutic strategies has been the subject of urgent investigation. With their immunomodulatory effects and ability to differentiate into a variety of cell types, MSCs have been considered a novel and effective therapeutic option for ALI. In a previous study, Lee et al. found that MSCs produce various soluble factors, including angiopoietin-1 (Ang-1), interleukin-10 (IL-10), keratinocyte growth factor (KGF), and prostaglandin E2 (PGE2), to improve lung epithelial and endothelial permeability, reduce inflammatory responses, enhance alveolar fluid clearance, and facilitate endothelial repair [37]. In addition, Khubutiya et al. demonstrated that these beneficial effects of MSCs on tissue repair mainly depended on their paracrine effects rather than differentiation ability [38]. Large-sample clinical trials evaluating the effects of MSCs on ALI are being conducted.

Recently, an increasing number of studies have focused on the strategies to enhance the therapeutic effectiveness of MSCs to widely promote the clinical administration of cellular therapy. Genetic modification is a particularly valuable approach because it directly integrates exogenous genes into cells to induce MSCs to produce desired proteins. To solve the problem of the low expression of homing receptors by MSCs, Yang et al. genetically overexpressed CXCR4 in MSCs using lentiviral vector transfection to enhance their homing efficiency and therapeutic effect in ALI [39]. Overexpressing IL-1 receptor-like-1 (ST2) could increase the antiinflammatory effect of MSCs on ALI via the interleukin33 (IL-33)/ST2 axis [40]. In addition, other studies focused on culturing MSCs with several specific cytokines or small molecule compounds to enhance their therapeutic effects. Witte et al. showed that prestimulation with inflammatory cytokines could enhance the immunomodulatory effects of UC-MSCs [41, 42]. Our previous study demonstrated that preconditioning UC-MSCs with rapamycin could increase cell migration and attenuate liver IRI via the CXCR4/CXCL12 axis [18]. In this study, we showed that heat shock (HS) pretreatment also enhanced the therapeutic potential of UC-MSCs during ALI. HS is a source of stress that facilitates organism and cell damage. However, recent studies showed that adaptive heat shock pretreatment could improve the viability and antiapoptotic properties of MSCs. Peng found that HS pretreatment effectively induced autophagy to decrease the apoptosis rate and increase the hepatoprotective effects of MSCs in liver IRI [21]. Other studies also reported that compared with MSCs, HSpretreated MSCs were better suited to repairing chemotherapy-induced premature ovarian failure and preventing cisplatin-induced granulosa cell apoptosis $[22,25]$. Inconsistent with the previous studies mentioned above, we directly selected HS conditions at $42{ }^{\circ} \mathrm{C}$ for $1 \mathrm{~h}$ according to Qing et al [22]. They proved that optimal HS condition was determined as $42^{\circ} \mathrm{C}$ for $1 \mathrm{~h}$ and recovering for $48 \mathrm{~h}$. The results of the biological characterization of the MSCs suggested that HS pretreatment did not affect the viability and antiapoptotic processes of the UC-MSCs. Furthermore, we established a mouse model of LPS-induced ALI, and the data indicated that the therapeutic effects of HS-pretreated UCMSCs during ALI were better than those of UC-MSCs.

In this study, we further detected the effect of HSpretreated UC-MSCs on macrophages, as macrophages 


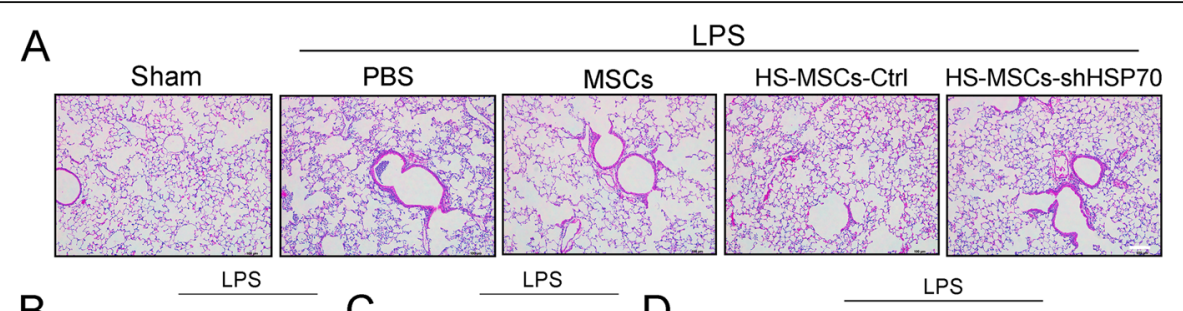

B

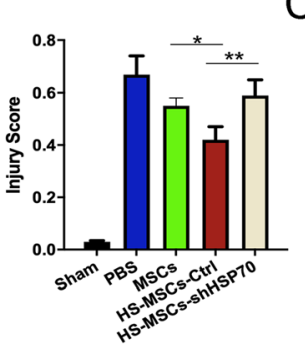

$\mathrm{C}^{8} \longrightarrow \mathrm{D}$

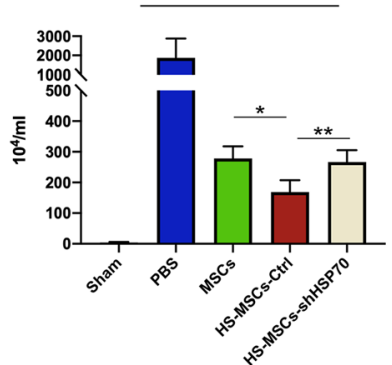

E
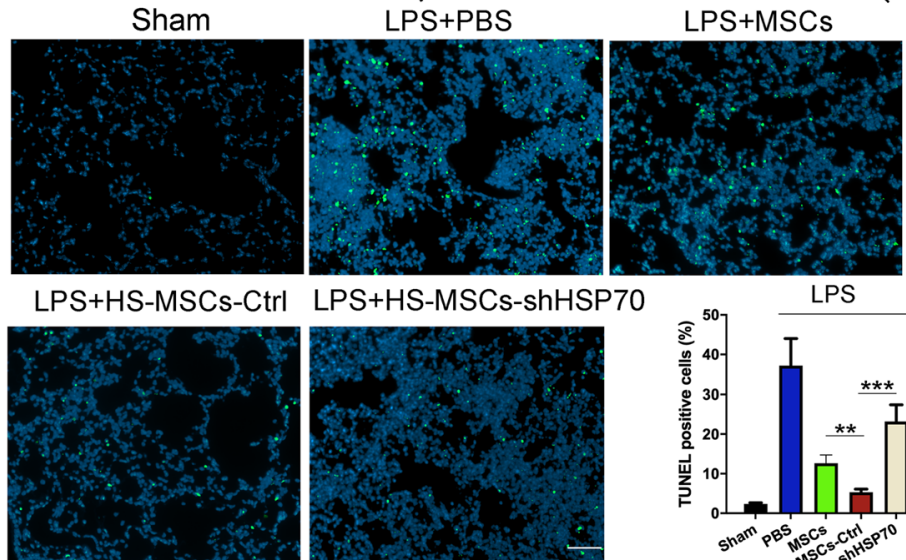

$\mathrm{F}$
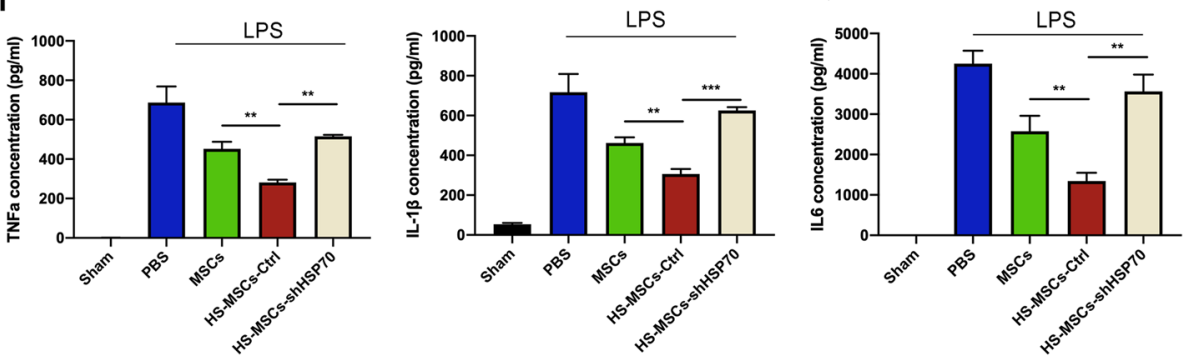

Fig. 6 The protective effect of HS-pretreated UC-MSCs on attenuating LPS-induced ALI by regulating HSP70. a Hematoxylin and eosin staining of lung tissues from each group to assess the amount of lung damage after ALI. Scale bar $200 \mu \mathrm{m}$. b The lung injury score of each group was calculated by selecting five fields of each section. The results are presented as the mean \pm SEM ( $n=5$ mice/group). $\mathbf{c}$ The wet/dry ratio of lung tissues from each group was obtained to evaluate lung edema. The results are presented as the mean \pm SEM ( $n=5$ mice/group). $\mathbf{d}$ The total cell count and neutrophil count in the BALF from each group were examined at $24 \mathrm{~h}$ after LPS treatment to assess the inflammatory response. The results are presented as the mean \pm SEM ( $n=5$ mice/group). e Representative images of TUNEL staining of lung sections from each group were collected. Scale bar $200 \mu \mathrm{m}$. The data are presented as the mean \pm SEM ( $n=5$ mice/group). $\mathbf{f}$ The levels of TNF-a, IL-1 $\beta$, and IL- 6 in BALF from each group were measured by ELISA. The data are presented as the mean \pm SEM ( $n=5$ mice/group). The data are expressed as the mean \pm SEM ( $n=3$ /group). ${ }^{*} p<0.05,{ }^{* *} p<0.01,{ }^{* *} p<0.001$ (all $p$ values were obtained by one-way ANOVA)

are critical immune cells that reside in the lung to mediate adaptive and innate immunity [43, 44]. In addition, macrophages are also known to be a heterogeneous population of immune cells and are mainly divided into two subgroups according to their functions and biomarkers. M1 macrophages have a proinflammatory phenotype, secrete various kinds of proinflammatory cytokines and chemokines, and play an important role in antigen presentation; in contrast, M2 macrophages are immunoregulatory cells that secrete IL-10 and TGF- $\beta$. During ALI, the activation of macrophages by LPS disrupts the balance of the immune status, and this effect is 
closely associated with a superabundant inflammatory response and subsequent lung injury [9]. Thus, recent studies have demonstrated that affecting macrophage polarization, which inhibits abnormally activated macrophages and promotes a regulatory phenotype, could be a therapeutic approach for ALI [45, 46]. By collecting BALF and culture supernatants, our in vivo and in vitro studies not only demonstrated the effect of UC-MSCs on regulating the phenotypic polarization of macrophages but also revealed that HS pretreatment enhanced the immunosuppressive effects of UC-MSCs, which further notably reduced the proportion of activated macrophages and increased polarization toward an immunoregulatory phenotype.

Mechanistically, activating macrophages with LPS upregulated TLR4 expression subsequently stimulated its downstream signaling pathway, including NF- $\mathrm{kB}, \mathrm{c}$-jun Nterminal kinase, and p38, and finally activated the NLRP3 inflammasome to synthesize various kinds of proinflammatory cytokines, such as IL-1 $\beta$ and IL-18 [47]. The imbalance of anti-inflammatory and proinflammatory responses leads to the progression of ALI. Previous research found that melatonin alleviated ALI by inhibiting the NLRP3 inflammasome [48]. Yin et al. performed in vivo and in vitro experiments to demonstrate that isoflurane acted as a therapeutic approach to improve LPSinduced ALI by inhibiting NLRP3 inflammasome activation in alveolar macrophages [49]. MSCs also play an important role in modulating inflammasome activation. In an in vitro study, Joo et al. found that MSCs inhibited Caspase- 1 activation and IL- $1 \beta$ secretion in activated macrophages by reducing the level of mitochondrial reactive oxygen species (ROS) [50]. In murine models of rheumatoid arthritis and Crohn's disease, Won and Serena et al. showed that MSCs could block inflammasome activation to regulate the immune properties of macrophages [51, 52]. In addition, Liu found that MSC-derived exosomes also reduced inflammasome activation in macrophages to alleviate LPS/galactosamine-induced acute liver failure via their encapsulated microRNAs [53]. In the present study, our results from the in vivo studies suggested that UCMSCs could notably inhibit NLRP3 inflammasome activation in lung tissues, and further in vitro studies revealed that MSCs could successfully block the expression of NLRP3, ASC, and cleaved-Caspase 1 in macrophage cell lines. In summary, we concluded MSCs may be utilized as a therapeutic approach to attenuate ALI by inhibiting NLRP3 inflammasome activation. Shi Yue et al. proved that heat shock transcription factor 1 (HSF1) activation promoted $\beta$-catenin expression, which led to NLRP3 inactivation and decreased I/R-induced liver injury. These authors indicated HSF1/ $\beta$-catenin signaling is a novel regulator of innate immunity during liver inflammatory injury [54]. Whether HS-pretreated MSCs modulate macrophages has not been reported until now. Interestingly, we also observed, for the first time, that HS pretreatment not only promoted the effects of MSCs in lung protection but also enhanced the potential of MSCs to modulate the NLRP3 inflammasome in macrophages. Wang et al. proved that MSC-derived PGE2 inhibited TGF- $\beta$-activated kinase 1 (TAK1) signaling and NLRP3 inflammasome activation in liver macrophages to decrease the production of inflammatory cytokines [55]. Therefore, in this study, we measured the levels of cytokines secreted by MSCs to determine how HS pretreatment enhanced the therapeutic potential of MSCs. Our findings suggested that HS pretreatment resulted in a decrease in NLRP3 inflammasome formation and IL- $1 \beta$ secretion by macrophages via enhancing PGE2 release. Cell death is induced by the NLRP3 inflammasome, and this form of cell death is called pyroptosis. In the lung, airway macrophages are critical for maintaining the functionality of airways via the clearance of inhaled particles, cell debris, and infectious agents [56]. MSC death modulation appears to be a decisive biological effect that could explain a significant portion of the therapeutic effects of MSCs [57, 58]. Other researchers found that exposing activated THP-1 cells with NLRP3 or ASC knocked down to indium-tin-oxide nanoparticles resulted in cell death without cytolysis, with deficiency in IL-1 $\beta /$ TNF- $\alpha$, and with features of apoptosis. Mesenchymal stem cells (MSCs) cocultured with macrophages inhibited both the inflammation and cell death induced by indium-tin-oxide nanoparticles [59]. As previous evidence from Fan et al. showed that HSP70 could upregulate COX-2 expression to promote inflammation, we finally detected the expression levels of members of a family of heat shock proteins that are substantially upregulated during stress conditions, including infection, oxidative stress, inflammation, and HS $[35,36]$. As expected, HS pretreatment induced HSP70 expression in MSCs. Our data from knocking down HSP70 in conjunction with investigating the effects of HS-pretreated MSCs on NLRP3 inflammasome activation in macrophages further confirmed the role of HS pretreatment in enhancing the immunoregulatory effects of MSCs.

In conclusion, the present study revealed that HS pretreatment can be used to enhance the immunoregulatory capacity of MSCs and to improve ALI. It is well known that the expression of heat shock proteins is highly induced after HS pretreatment. Our findings of increased HSP70 expression in UC-MSCs indicate that a high level of HSP70 enhances PGE2 secretion by UC-MSCs, which inhibits NLRP3 inflammasome activation in macrophages. Therefore, HS pretreatment may be a promising strategy to enhance the therapeutic potential of MSCs in the treatment of ALI in the clinic. 


\section{Abbreviations}

LPS: Lipopolysaccharide; ALI: Acute lung injury; MSCs: Mesenchymal stem cells; UC-MSCs: Umbilical cord-derived mesenchymal stem cells; HS: Heat shock; HSP70: Heat shock protein 70; BALF: Bronchoalveolar lavage fluid; ARDS: Acute respiratory distress syndrome; IRI: Ischemia/ reperfusion injury; Ang-1: Angiopoietin-1; IL-10: Interleukin-10; KGF: Keratinocyte growth factor; PGE2: Prostaglandin E2; PBS: Phosphate-buffered saline;

PFA: Paraformaldehyde; qRT-PCR: Quantitative real-time reverse transcriptasepolymerase chain reaction; MSC-CM: MSC conditioned medium;

ELISA: Enzyme-linked immunosorbent assay; RIPA: Radioimmunoprecipitation assay; EDTA: Ethylene diamine tetraacetic acid; SEM: Standard error of the mean; COXs: Cyclooxygenases

\section{Supplementary Information}

The online version contains supplementary material available at https://doi. org/10.1186/s13287-021-02328-3.

\section{Additional file 1.}

\section{Acknowledgements}

Not applicable.

\section{Authors' contributions}

H. LV, X. Yuan, and J. Zhang: collection and/or assembly of data, data analysis, and interpretation, and manuscript writing. T. Lu, J. Yao, J. Zheng, and J. Cai: provision of study material. J. Xiao, H. Chen, S. Xie, and Y. Ruan: collection and/or assembly of data. H. Yi, X. Sui, and Y. An: conception and design and final approval of manuscript. The authors read and approved the final manuscript.

\section{Funding}

This work was supported by the grants from the National key research and development program (2017YFA0104304), National Natural Science Foundation of China $(81570593,81670601,81770648,81802402,81870449$, 81901943, 81900597, 31701116), Guangdong Natural Science Foundation (2015A030312013, 2018A030310323, 2018A030310275, 2021A1515012382), Sci-tech Research Development Program of Guangdong province (2017A020215023), Medical Scientific Research Foundation of Guangdong Province (A2018130), Sci-tech Research Development Program of Guangzhou city (158100076) and Young Teacher Development Program of Sun Yat-Sen University (17ykpy57, 20ykpy33), the China Postdoctoral Science Foundation (2019 M653199), and the Fundamental Research Funds for the Sun Yat-sen Universities (18zxxt08).

\section{Availability of data and materials}

The datasets used and/or analyzed during the current study are available from the corresponding author on reasonable request.

\section{Declarations}

\section{Ethics approval and consent to participate}

The procedures of isolated UC-MSCs was conducted abiding by the Declaration of Helsinki and was approved by the Research Ethics Committee of the Third Affiliated Hospital of Sun Yat-sen University (Guangzhou, China).

\section{Consent for publication}

Not applicable.

\section{Competing interests}

The authors declare that they have no competing interests.

\section{Author details}

'Department of Surgical Intensive Care Unit, the Third Affiliated Hospital of Sun Yat-sen University, Guangzhou 510630, Guangdong Province, China. ${ }^{2}$ Guangdong Key Laboratory of Liver Disease Research, Key Laboratory of Liver Disease Biotherapy and Translational Medicine of Guangdong Higher Education Institutes, the Third Affiliated Hospital of Sun Yat-sen University, Guangzhou 510630, China. ${ }^{3}$ Department of General Intensive Care Unit, The Third Affiliated Hospital of Sun Yat-sen University, Guangzhou 510630, China.
${ }^{4}$ Department of Hepatic Surgery and Liver Transplantation Center, The Third Affiliated Hospital of Sun Yat-sen University, Guangzhou 510630, China.

${ }^{5}$ Vaccine Research Institute of Sun Yat-sen University, Biotherapy Center, The Third Affiliated Hospital of Sun Yat-sen University, Guangzhou, China.

${ }^{6}$ Department of Thyroid and Breast Surgery, The Third Affiliated Hospital of Sun Yat-sen University, Guangzhou 510630, China.

Received: 1 January 2021 Accepted: 7 April 2021

Published online: 17 May 2021

\section{References}

1. Tagami T, Sakka SG, Monnet X. Diagnosis and treatment of acute respiratory distress syndrome. JAMA. 2018;320(3):305. https://doi.org/10.1001/jama.2018. 5924.

2. Ben Salem C. Acute respiratory distress syndrome. N Engl J Med. 2017; 377(19):1904-5. https://doi.org/10.1056/NEJMc1711824.

3. Villar J, Blanco J, Kacmarek RM. Current incidence and outcome of the acute respiratory distress syndrome. Curr Opin Crit Care. 2016;22:1-6. https://doi. org/10.1097/MCC.0000000000000266.

4. Bellani G, Laffey JG, Pham T, Fan E, Brochard L, Esteban A, et al. Epidemiology, patterns of care, and mortality for patients with acute respiratory distress syndrome in intensive care units in 50 countries. JAMA. 2016;315(8):788-800. https://doi.org/10.1001/jama.2016.0291.

5. Lawler PR, Fan E. Heterogeneity and phenotypic stratification in acute respiratory distress syndrome. Lancet Respir Med. 2018;6(9):651-3. https:// doi.org/10.1016/S2213-2600(18)30287-X.

6. Samary CS, et al. Lung functional and biologic responses to variable ventilation in experimental pulmonary and extrapulmonary acute respiratory distress syndrome. Crit Care Med. 2016;44:e553-62. https://doi. org/10.1097/CCM.0000000000001611.

7. Long ME, et al. JCl Insight. 2019;4. https://doi.org/10.1172/jci.insight.132377.

8. Mosser DM, Edwards JP. Exploring the full spectrum of macrophage activation. Nat Rev Immunol. 2008;8(12):958-69. https://doi.org/10.1038/ nri2448.

9. Johnston LK, Rims CR, Gill SE, McGuire JK, Manicone AM. Pulmonary macrophage subpopulations in the induction and resolution of acute lung injury. Am J Respir Cell Mol Biol. 2012;47(4):417-26. https://doi.org/10.1165/ rcmb.2012-00900C.

10. Li S, Zheng X, Li H, Zheng J, Chen X, Liu W, et al. Mesenchymal stem cells ameliorate hepatic ischemia/reperfusion injury via inhibition of neutrophil recruitment. J Immunol Res. 2018;2018:7283703-10. https://doi.org/10.11 55/2018/7283703.

11. Pan GZ, Yang Y, Zhang J, Liu W, Wang GY, Zhang YC, et al. Bone marrow mesenchymal stem cells ameliorate hepatic ischemia/reperfusion injuries via inactivation of the MEK/ERK signaling pathway in rats. J Surg Res. 2012; 178(2):935-48. https://doi.org/10.1016/j.jss.2012.04.070.

12. Feng $Y$, Wang L, Ma X, Yang X, Don O, Chen X, et al. Effect of hCMSCs and liraglutide combination in ALl through CAMP/PKAc/beta-catenin signaling pathway. Stem Cell Res Ther. 2020;11(1):2. https:/doi.org/10.1186/s13287-019-1492-6.

13. Caretti A, Peli V, Colombo M, Zulueta A. Lights and shadows in the use of mesenchymal stem cells in lung inflammation, a poorly investigated topic in cystic fibrosis. Cells. 2019;9. https://doi.org/10.3390/cells9010020.

14. Mokhber Dezfouli MR, Jabbari Fakhr M, Sadeghian Chaleshtori S, Dehghan MM, Vajhi A, Mokhtari R. Intrapulmonary autologous transplant of bone marrow-derived mesenchymal stromal cells improves lipopolysaccharideinduced acute respiratory distress syndrome in rabbit. Crit Care. 2018;22(1): 353. https://doi.org/10.1186/s13054-018-2272-X.

15. Liu G, Lv H, An Y, Wei X, Yi X, Yi H. Tracking of transplanted human umbilical cord-derived mesenchymal stem cells labeled with fluorescent probe in a mouse model of acute lung injury. Int J Mol Med. 2018;41:252734. https://doi.org/10.3892/ijmm.2018.3491.

16. Wei X, Yi X, Lv H, Sui X, Lu P, Li L, et al. MicroRNA-377-3p released by mesenchymal stem cell exosomes ameliorates lipopolysaccharide-induced acute lung injury by targeting RPTOR to induce autophagy. Cell Death Dis. 2020;11(8):657. https://doi.org/10.1038/s41419-020-02857-4.

17. $L v H$, et al. Mesenchymal stromal cells ameliorate acute lung injury induced by LPS mainly through stanniocalcin-2 mediating macrophage polarization. Ann Transl Med. 2020;8:334. https://doi.org/10.21037/atm.2020.02.105.

18. Zheng J, Li H, He L, Huang Y, Cai J, Chen L, et al. Preconditioning of umbilical cord-derived mesenchymal stem cells by rapamycin increases cell migration and ameliorates liver ischaemia/reperfusion injury in mice via the 
CXCR4/CXCL12 axis. Cell Prolif. 2019;52(2):e12546. https://doi.org/10.1111/ cpr.12546.

19. Sart S, Ma T, Li Y. Preconditioning stem cells for in vivo delivery. Biores Open Access. 2014;3(4):137-49. https://doi.org/10.1089/biores.2014.0012.

20. Choudhery MS, Badowski M, Muise A, Harris DT. Effect of mild heat stress on the proliferative and differentiative ability of human mesenchymal stromal cells. Cytotherapy. 2015;17(4):359-68. https://doi.org/10.1016/j.jcyt.2 014.11.003.

21. Qiao PF, Yao L, Zhang XC, Li GD, Wu DQ. Heat shock pretreatment improves stem cell repair following ischemia-reperfusion injury via autophagy. World I Gastroenterol. 2015;21(45):12822-34. https://doi.org/10.3 748/wjg.v21.i45.12822.

22. Wang $Q$, Li X, Wang $Q$, Xie J, Xie C, Fu X. Heat shock pretreatment improves mesenchymal stem cell viability by heat shock proteins and autophagy to prevent cisplatin-induced granulosa cell apoptosis. Stem Cell Res Ther. 2019; 10(1):348. https://doi.org/10.1186/s13287-019-1425-4.

23. Gao F, Hu X, Xie X, Liu X, Wang J. Heat shock protein 90 stimulates rat mesenchymal stem cell migration via PI3K/Akt and ERK1/2 pathways. Cell Biochem Biophys. 2015;71(1):481-9. https://doi.org/10.1007/s12013-014-022 8-6.

24. Yao J, Zheng J, Cai J, Zeng K, Zhou C, Zhang J, et al. Extracellular vesicles derived from human umbilical cord mesenchymal stem cells alleviate rat hepatic ischemia-reperfusion injury by suppressing oxidative stress and neutrophil inflammatory response. FASEB J. 2019;33(2):1695-710. https://doi. org/10.1096/fj.201800131RR.

25. Chen X, Wang Q, Li X, Wang Q, Xie J, Fu X. Heat shock pretreatment of mesenchymal stem cells for inhibiting the apoptosis of ovarian granulosa cells enhanced the repair effect on chemotherapy-induced premature ovarian failure. Stem Cell Res Ther. 2018;9(1):240. https://doi.org/10.1186/ s13287-018-0964-4.

26. Gielkens AL, Ressang AA, ljzermann J, Quak J. Test protocol of an enzymelinked immunosorbent assay (ELISA) for the detection of antibodies against bovine leukosis virus. Vet Q. 1981;3(1):34-7. https://doi.org/10.1080/016521 76.1981 .9693792$.

27. Mei SH, et al. Prevention of LPS-induced acute lung injury in mice by mesenchymal stem cells overexpressing angiopoietin 1. Plos Med. 2007:4(9): e269. https://doi.org/10.1371/journal.pmed.0040269.

28. Su VY, Lin CS, Hung SC, Yang KY. Mesenchymal stem cell-conditioned medium induces neutrophil apoptosis associated with inhibition of the NFkappaB pathway in endotoxin-induced acute lung injury. Int J Mol Sci. 2019; 20. https://doi.org/10.3390/ijms20092208.

29. Matute-Bello G, Downey G, Moore BB, Groshong SD, Matthay MA, Slutsky AS, et al. An official American Thoracic Society workshop report: features and measurements of experimental acute lung injury in animals. Am J Respir Cell Mol Biol. 2011;44(5):725-38. https://doi.org/10.1165/rcmb.20090210ST.

30. Liu C, Lou W, Yang JC, Liu L, Armstrong CM, Lombard AP, et al. Proteostasis by STUB1/HSP70 complex controls sensitivity to androgen receptor targeted therapy in advanced prostate cancer. Nat Commun. 2018;9(1):4700. https://doi.org/10.1038/s41467-018-07178-x.

31. Morrison TJ, Jackson MV, Cunningham EK, Kissenpfennig A, McAuley DF, O'Kane CM, et al. Mesenchymal stromal cells modulate macrophages in clinically relevant lung injury models by extracellular vesicle mitochondrial transfer. Am J Respir Crit Care Med. 2017;196(10):1275-86. https://doi.org/1 0.1164/rccm.201701-01700C

32. Chambers ED, White A, Vang A, Wang Z, Ayala A, Weng T, et al. Blockade of equilibrative nucleoside transporter $1 / 2$ protects against Pseudomonas aeruginosa-induced acute lung injury and NLRP3 inflammasome activation. FASEB J. 2020;34(1):1516-31. https://doi.org/1 0.1096/fj.201902286R.

33. Ip WKE, Hoshi N, Shouval DS, Snapper S, Medzhitov R. Anti-inflammatory effect of IL-10 mediated by metabolic reprogramming of macrophages. Science. 2017;356(6337):513-9. https://doi.org/10.1126/science.aal3535.

34. Park HJ, Kim J, Saima FT, Rhee KJ, Hwang S, Kim MY, et al. Adipose-derived stem cells ameliorate colitis by suppression of inflammasome formation and regulation of $\mathrm{M} 1$-macrophage population through prostaglandin $\mathrm{E} 2$. Biochem Biophys Res Commun. 2018;498(4):988-95. https://doi.org/10.1016/ j.bbrc.2018.03.096.

35. Bianchi A, Moulin D, Hupont S, Koufany M, Netter P, Reboul P, et al. Oxidative stress-induced expression of HSP70 contributes to the inhibitory effect of 15d-PGJ2 on inducible prostaglandin pathway in chondrocytes.
Free Radic Biol Med. 2014;76:114-26. https://doi.org/10.1016/j.freera dbiomed.2014.07.028.

36. Zhang F, Hackett NR, Lam G, Cheng J, Pergolizzi R, Luo L, et al. Green fluorescent protein selectively induces HSP70-mediated up-regulation of COX-2 expression in endothelial cells. Blood. 2003;102(6):2115-21. https:// doi.org/10.1182/blood-2003-01-0049.

37. Lee JW, Fang X, Krasnodembskaya A, Howard JP, Matthay MA. Concise review: Mesenchymal stem cells for acute lung injury: role of paracrine soluble factors. Stem Cells. 2011;29(6):913-9. https://doi.org/10.1002/stem. 643.

38. Khubutiya MS, Vagabov AV, Temnov AA, Sklifas AN. Paracrine mechanisms of proliferative, anti-apoptotic and anti-inflammatory effects of mesenchymal stromal cells in models of acute organ injury. Cytotherapy. 2014;16(5):579-85. https://doi.org/10.1016/j.jcyt.2013.07.017.

39. Yang JX, Zhang N, Wang HW, Gao P, Yang QP, Wen QP. CXCR4 receptor overexpression in mesenchymal stem cells facilitates treatment of acute lung injury in rats. J Biol Chem. 2015;290(4):1994-2006. https://doi.org/10.1 074/jbc.M114.605063.

40. Yagami A, Orihara K, Morita H, Futamura K, Hashimoto N, Matsumoto K, et al. IL-33 mediates inflammatory responses in human lung tissue cells. J Immunol. 2010;185(10):5743-50. https://doi.org/10.4049/jimmunol.0903818.

41. de Witte SFH, Merino AM, Franquesa M, Strini T, van Zoggel JAA, Korevaar SS, et al. Cytokine treatment optimises the immunotherapeutic effects of umbilical cord-derived MSC for treatment of inflammatory liver disease. Stem Cell Res Ther. 2017;8(1):140. https://doi.org/10.1186/s13287-017-0590-6.

42. de Witte SFH, Luk F, Sierra Parraga JM, Gargesha M, Merino A, Korevaar SS, et al. Immunomodulation by therapeutic mesenchymal stromal cells (MSC) is triggered through phagocytosis of MSC by monocytic cells. Stem Cells. 2018;36(4):602-15. https://doi.org/10.1002/stem.2779.

43. Biswas SK, Mantovani A. Macrophage plasticity and interaction with lymphocyte subsets: cancer as a paradigm. Nat Immunol. 2010;11(10):88996. https://doi.org/10.1038/ni.1937.

44. Mittal M, Tiruppathi C, Nepal S, Zhao YY, Grzych D, Soni D, et al. TNFalphastimulated gene-6 (TSG6) activates macrophage phenotype transition to prevent inflammatory lung injury. Proc Natl Acad Sci U S A. 2016;113(50): E8151-8. https://doi.org/10.1073/pnas.1614935113.

45. Nepal S, Tiruppathi C, Tsukasaki Y, Farahany J, Mittal M, Rehman J, et al. STAT6 induces expression of Gas6 in macrophages to clear apoptotic neutrophils and resolve inflammation. Proc Natl Acad Sci U S A. 2019: 116(33):16513-8. https://doi.org/10.1073/pnas.1821601116.

46. Cho, S. J. et al. DROSHA-dependent AIM2 inflammasome activation contributes to lung inflammation during idiopathic pulmonary fibrosis. Cells 8, doi:https://doi.org/10.3390/cells8080938 (2019).

47. Del Campo JA, Gallego P, Grande L. Role of inflammatory response in liver diseases: therapeutic strategies. World J Hepatol. 2018;10(1):1-7. https://doi. org/10.4254/wjh.v10.11.1.

48. Zhang Y, Li X, Grailer JJ, Wang N, Wang M, Yao J, et al. Melatonin alleviates acute lung injury through inhibiting the NLRP3 inflammasome. J Pineal Res. 2016;60(4):405-14. https://doi.org/10.1111/jpi.12322.

49. Yin N, Peng Z, Li B, Xia J, Wang Z, Yuan J, et al. Isoflurane attenuates lipopolysaccharide-induced acute lung injury by inhibiting ROS-mediated NLRP3 inflammasome activation. Am J Transl Res. 2016;8(5):2033-46.

50. Oh JY, Ko JH, Lee HJ, Yu JM, Choi H, Kim MK, et al. Mesenchymal stem/ stromal cells inhibit the NLRP3 inflammasome by decreasing mitochondrial reactive oxygen species. Stem Cells. 2014;32(6):1553-63. https://doi.org/10.1 002/stem.1608.

51. Shin TH, Kim HS, Kang TW, Lee BC, Lee HY, Kim YJ, et al. Human umbilical cord blood-stem cells direct macrophage polarization and block inflammasome activation to alleviate rheumatoid arthritis. Cell Death Dis. 2016;7(12):e2524. https://doi.org/10.1038/cddis.2016.442.

52. Serena C, Keiran N, Madeira A, Maymó-Masip E, Ejarque M, Terrón-Puig M, et al. Crohn's disease disturbs the immune properties of human adiposederived stem cells related to inflammasome activation. Stem Cell Rep. 2017; 9(4):1109-23. https://doi.org/10.1016/.jstemcr.2017.07.014.

53. Liu Y, Lou G, Li A, Zhang T, Qi J, Ye D, et al. AMSC-derived exosomes alleviate lipopolysaccharide/d-galactosamine-induced acute liver failure by miR-17-mediated reduction of TXNIP/NLRP3 inflammasome activation in macrophages. EBioMedicine. 2018:36:140-50. https://doi.org/10.1016/j. ebiom.2018.08.054.

54. Yue S, Zhu J, Zhang M, Li C, Zhou X, Zhou M, et al. The myeloid heat shock transcription factor $1 /$ beta-catenin axis regulates NLR family, pyrin domain- 
containing 3 inflammasome activation in mouse liver ischemia/reperfusion injury. Hepatology. 2016;64(5):1683-98. https://doi.org/10.1002/hep.28739.

55. Wang J, Liu Y, Ding H, Shi X, Ren H. Mesenchymal stem cell-secreted prostaglandin E2 ameliorates acute liver failure via attenuation of cell death and regulation of macrophage polarization. Stem Cell Res Ther. 2021;12(1): 15. https://doi.org/10.1186/s13287-020-02070-2.

56. Shotland AM, Fontenot AP, McKee AS. Pulmonary macrophage cell death in lung health and disease. Am J Respir Cell Mol Biol. 2020. https://doi.org/1 0.1165/rcmb.2020-0420TR.

57. Naji A, Suganuma N, Espagnolle N, Yagyu Kl, Baba N, Sensebé L, et al. Rationale for determining the functional potency of mesenchymal stem cells in preventing regulated cell death for therapeutic use. Stem Cells Transl Med. 2017;6(3):713-9. https://doi.org/10.5966/sctm.2016-0289.

58. Naji A, Favier B, Deschaseaux F, Rouas-Freiss N, Eitoku M, Suganuma N. Mesenchymal stem/stromal cell function in modulating cell death. Stem Cell Res Ther. 2019;10(1):56. https://doi.org/10.1186/s13287-019-1158-4.

59. Naji A, Muzembo BA, Yagyu KI, Baba N, Deschaseaux F, Sensebé L, et al. Endocytosis of indium-tin-oxide nanoparticles by macrophages provokes pyroptosis requiring NLRP3-ASC-Caspase1 axis that can be prevented by mesenchymal stem cells. Sci Rep. 2016;6(1):26162. https://doi.org/10.1038/ srep26162.

\section{Publisher's Note}

Springer Nature remains neutral with regard to jurisdictional claims in published maps and institutional affiliations.

Ready to submit your research? Choose BMC and benefit from:

- fast, convenient online submission

- thorough peer review by experienced researchers in your field

- rapid publication on acceptance

- support for research data, including large and complex data types

- gold Open Access which fosters wider collaboration and increased citations

- maximum visibility for your research: over $100 \mathrm{M}$ website views per year

At BMC, research is always in progress.

Learn more biomedcentral.com/submissions 